\title{
¿Cómo se rehace una clase social? Una reflexión crítica sobre los esquemas de clase instituidos
}

\section{What remakes a social class? A critical reflection on stablished class schemes}

Gonzalo Seid

gonzaloseid@gmail.com

CONICET, Argentina

Universidad de Buenos Aires, Argentina

Recepción: 01 Septiembre 2020

Aprobación: 01 Marzo 2021

Publicación: 02 Agosto 2021

Cita sugerida: Seid, G. (2021). ¿Cómo se rehace una clase social? Una reflexión crítica sobre los esquemas de clase instituidos. Cuestiones de Sociología, 25, e124. https://doi.org/10.24215/23468904e124
Resumen: Este artículo se propone discutir la pertinencia de los esquemas habitualmente utilizados en el análisis de clase y movilidad social, a partir de resultados de investigación cualitativa en la temática. Se seleccionaron, de un conjunto más amplio, once relatos de vida familiares de individuos residentes en el Área Metropolitana de Buenos Aires, con los cuales se reconstruyeron sus trayectorias de clase social, es decir, los itinerarios entre posiciones en el espacio social de las generaciones precedentes y de los propios entrevistados. Mediante el examen de la información disponible en los relatos de vida sobre ocupaciones, educación y otros indicadores de distintas especies de capital, se está en condiciones de establecer lo fundamental de estas trayectorias de (in)movilidad social, los recorridos entre posiciones de la estructura social. Sin embargo, los resultados de este análisis no concuerdan con las clasificaciones que la misma información conduciría a efectuar si se trabajara con el esquema de clases más utilizado en la investigación estándar en la temática. A partir de esta discordancia, se reflexiona sobre lo que las clasificaciones de clases sociales implican, lo que revelan y lo que ocultan.

Palabras clave: Clase social, Trayectorias, Relatos de vida, Esquemas de clase, Movilidad social.

Abstract: This article discusses, based on qualitative research results, the relevance of the stablished class schemes in class analysis and social mobility. We selected, from a broader set, eleven family life stories of individuals residing in the Buenos Aires Metropolitan Area, and we reconstructed their social class trajectories, that is, the itineraries between positions across the social space of precedent generations and the interviewees themselves. By examining the information available in the life stories on occupations, education and other indicators of different capital species, it is possible to establish the essentials of these trajectories of social (in) mobility, the itineraries between positions in the Social structure. However, the results of this analysis do not agree with the classifications that the same information would lead to make if one worked with the class scheme most used in standard research on the subject. From this disagreement, one reflects on what the classifications of social classes imply, what they reveal and what they hide.

Keywords: Social class, Trajectories, Life stories, Class schemes, Social mobility. 


\section{Introducción}

El análisis de clase y movilidad social constituye un campo de estudios clásico de la sociología, en el cual la experiencia de décadas de investigación se ha plasmado en lo que podríamos llamar el abordaje estándar de la movilidad social. Decimos estándar en su doble acepción: "que sirve como tipo, modelo, norma, patrón o referencia" - definición de la RAE- y, a su vez, en este caso, porque se trata de investigación mediante métodos cuantitativos, que estandarizan la información. Desde los estudios pioneros de Pitirim Sorokin hace un siglo se ha recorrido un largo camino en el campo de la movilidad social. Las primeras aproximaciones mediante tablas de movilidad simples, luego el enfoque del logro de status, y las actuales mediciones de movilidad relativa o fluidez social mediante modelos log-lineales, han constituido las líneas de investigación preponderantes. Tras señalar las limitaciones de toda esta corriente de abordaje estándar, investigadores como Lorenzo Cachón Rodríguez (1989) y Daniel Bertaux y Paul Thompson (2007) han planteado la necesidad de abordajes alternativos de la movilidad social, de renovar las perspectivas cognitivas para visualizar los mecanismos de las trayectorias de clase que se omiten o dan por sentados.

En América Latina y en particular en Argentina la temática de clases y movilidad social ha sido abordada tanto desde los enfoques cuantitativos estándar como a través de aproximaciones cualitativas o mixtas. Los estudios de Germani sobre la estructura social argentina inauguraron la tradición local de investigación en clases y movilidad social (véase la compilación Germani, Mera y Rebón, 2010). Investigadores como Beccaria (1978), Torrado (1992), Sautu (1992) y Jorrat (2000) continuaron el legado durante las últimas décadas del siglo XX. En el presente siglo tuvo lugar una nueva oleada de interés por la movilidad social, en la que numerosos/as investigadores/as hicieron aportes específicos, a menudo combinando metodologías cuantitativas y cualitativas (Chávez Molina, Pla y Molina Derteano, 2011; Dalle, 2016; Pla, 2016; Jiménez Zunino y Assusa, 2017). En algunos estudios cualitativos hubo aproximaciones indirectas a la movilidad social a partir de las trayectorias laborales (Muñiz Terra, 2016), las transiciones entre instituciones educativas y mercado laboral (Jacinto, 2010), o la reproducción social en condiciones de pobreza (Gutiérrez, 2015), entre otras.

Este clima de desarrollo de investigaciones sobre clases y movilidad social en Argentina, que desde 2011 tuvo al Seminario Internacional Desigualdad y Movilidad Social en América Latina como un importante espacio de intercambios, posiblemente haya estado vinculado a la recomposición económica argentina en la década posterior a la crisis de 2002. Junto al crecimiento económico, disminuyeron algunas desigualdades, pero hubo otras que se mantuvieron o se intensificaron (Kessler, 2014). Las tendencias contrapuestas implicaron un desafío para comprender las permanencias y las transformaciones de la estructura social argentina y de América Latina.

Abrevando en estas discusiones colectivas respecto de las clases sociales y la movilidad en la Argentina contemporánea, en el presente artículo se desarrollan algunas reflexiones en torno a los esquemas de clase, a partir de una experiencia de investigación cualitativa. El punto de partida teórico de dicha investigación 
ha sido la teoría de las clases sociales de Pierre Bourdieu, desarrollada a lo largo de toda su obra, pero especialmente en La Distinción y en Cómo se hace una clase social. ${ }^{1}$ Conceptos como espacio social, formas de capital, disposiciones subjetivas, estrategias y prácticas, de uso extendido en la sociología contemporánea, fueron utilizados en esta ocasión para abordar preguntas relativas a las trayectorias de movilidad social de individuos en familias. El problema de investigación discurrió sobre qué configuraciones de formas de capital, condicionamientos sociales y disposiciones subjetivas familiares se presentaron en las trayectorias de clase de mujeres y varones en distintas posiciones del espacio social, residentes en el Área Metropolitana de Buenos Aires en 2015. Se reconstruyeron a partir de relatos de vida y árboles genealógicos las trayectorias de 35 individuos -y sus familias-, nacidos entre mediados de la década del sesenta y mediados de la década siguiente. La muestra se segmentó según ocupación de los padres (obreros, empleados, comerciantes, profesionales).

No se pretende desarrollar aquí los resultados de aquella investigación, ${ }^{2}$ sino consignar solamente las informaciones e interpretaciones necesarias para el presente ejercicio de reflexión. Para este trabajo, de la serie total de treinta y cinco relatos de vida -que fueron analizados desde las inquietudes y búsquedas del abordaje alternativo de Bertaux a través de la teoría de las clases de Bourdieu-, se seleccionó un subconjunto de once casos. Estos últimos fueron seleccionados por reunir características de interés que se expondrán en los siguientes apartados. Por ende, lo que se afirme no aplica a los restantes 24 casos de la investigación.

Luego de presentar una síntesis de las historias de los casos seleccionados, se confrontan estas trayectorias con un esquema de clases en particular: el esquema de Goldthorpe y colaboradores (Erikson, Goldthorpe y Portocarero, 1979). Con esta confrontación como disparador, se realizan algunas reflexiones acerca de los modos de pensar las clases sociales y sus implicancias en el análisis de clase y movilidad social.

\section{Los casos seleccionados}

A continuación, se presenta una apretada síntesis de cada caso de modo tal de contar con la información indispensable para comprender la trayectoria de movilidad social en cuestión. La información surge de entrevistas biográficas realizadas en el año 2015. Los casos seleccionados nacieron 1966 y 1975 y residen actualmente en el Área Metropolitana de Buenos Aires.

Carlos. Su padre trabajó como gerente en varias empresas y fue durante algún tiempo dueño de un frigorífico. Su madre fue empleada administrativa hasta que contrajo matrimonio. Cuando Carlos terminó la secundaria, tras una grave pelea familiar, abandonó el hogar de su familia y prácticamente se interrumpieron los vínculos. Fue a vivir con un amigo, trabajó como administrativo y como profesor particular, y estudió la carrera de contabilidad. Antes de terminar la universidad, ingresó como analista contable en una empresa multinacional. Allí ha hecho carrera durante un cuarto de siglo, hasta alcanzar posiciones gerenciales.

Lucas. Su madre era escribana y su padre contador en una empresa agropecuaria. La familia de la abuela paterna poseía una quinta en las afueras de Buenos Aires donde cultivaban para autoconsumo y para la venta. Con el tiempo esa quinta pasó a estar integrada al tejido urbano, fue el emplazamiento 
de varias viviendas familiares -entre ellas la de la familia de Lucas-. Luego las viviendas fueron puestas en alquiler. En contacto con el mundo agropecuario por el trabajo de su padre, Lucas se interesó por la agronomía, carrera que pudo cursar sin tener que trabajar en paralelo, excepto de manera ocasional como profesor particular. Lucas está casado con una psicóloga, con quien tuvieron dos hijos. Como agrónomo, los viajes por trabajo han sido algo recurrente. Su esposa en una primera etapa lo acompañó y luego permaneció en Buenos Aires ocupándose de la crianza de los hijos, además de su propio trabajo. Lucas hizo carrera en una multinacional de productos agrícolas, donde alcanzó cargos gerenciales. Actualmente, trabaja como consultor independiente, asesorando a empresas distribuidoras de productos agrícolas.

Felipe. Su padre era contador público e hizo su carrera laboral en una de las empresas públicas más importantes de Argentina, donde llegó a ocupar puestos gerenciales en la década de 1980. Su madre, de familia de empresarios imprenteros, estudió música y trabajó la mayor parte de su vida en comercios propios de librería e imprenta. En su niñez, Felipe pasó por varios colegios. $\mathrm{Su}$ trayectoria escolar estuvo marcada por asiduas sanciones disciplinarias, tratamientos por parte de psicólogos escolares, y por la repitencia. A los trece años se le manifestó un problema cardíaco que requirió una compleja intervención quirúrgica. Tras ese momento de inflexión se le agudizaron algunos problemas de salud mental, a su vez agravados por adicciones. Alrededor de los dieciséis años abandonó la escuela secundaria y trabajó en el comercio de su madre. Luego inauguraron otro comercio con su hermano, el cual no prosperó. En ningún trabajo permaneció demasiado tiempo: pasó por un sinnúmero de labores de baja calificación.

Lara. Ya sus bisabuelos fueron dueños de un hotel y su abuelo tuvo almacenes y restoranes. El padre de Lara trabajó en los distintos emprendimientos que fue teniendo su padre y su familia: en el hotel, en restoranes y en un criadero de pollos con granja de venta al público. En la época de mayor prosperidad en la década de 1980 llegaron a tener cerca de veinte empleados entre dos negocios en simultáneo. Durante la década siguiente estos fueron dejando de ser rentables, hasta que entró en quiebra el último comercio. Los alquileres del local y los salarios adeudados los forzaron a vender inmuebles para saldar las cuentas. Los padres de Lara se convirtieron en asalariados; la madre como empleada administrativa y el padre como vigilador privado. También Lara, quien debió trabajar durante la cursada de su carrera de veterinaria, que le insumió doce años.

Domingo. Sus padres eran pequeños comerciantes, que pasaron por distintos rubros. Desde pequeño, trabajó con su padre en una verdulería, en una época en que la familia se turnaba para atender tres comercios que poseían simultáneamente. Ocupado en trabajar junto a su padre, Domingo abandonó la secundaria, a diferencia de su hermana que llegó a graduarse en la universidad. Sin embargo, los comercios no perduraron y debieron probar suerte con otros rubros, como un bodegón familiar, y luego como remiseros. Tras la muerte de su padre, Domingo trabajó como fletero y luego como empleado en un taller mecánico. Cuando este cerró, Domingo abrió un puesto de flores. Si bien es suyo el comercio, sus ganancias son tan exiguas que apenas le alcanzan para subsistir.

Ricardo. En su familia todos eran comerciantes. Sus abuelos comenzaron como vendedores ambulantes y fueron progresando. La familia materna ya tenía 
algunas propiedades inmuebles y varios comercios atendidos entre los miembros de la familia. La familia paterna era más pobre, eran vendedores ambulantes. Con la ayuda de la familia política, el padre de Ricardo pudo abrir un comercio de ropa, que mantuvo hasta que se jubiló. Sus cuñados, en cambio, ya para esa época pusieron en alquiler los locales para vivir de las rentas. Ricardo abandonó la secundaria por propia elección. Trabajó muchos años junto a su padre, pero como el negocio no rendía lo suficiente, invirtió en un puesto de diarios. Obtuvo suficientes ingresos para ahorrar y adquirir una vivienda, que convirtió en dos locales para poner en alquiler. Luego, sumando sus propios ingresos a las herencias de sus tíos y de sus padres, replicó la inversión tres veces más, haciéndose de varios ingresos por alquileres que le permitieron dejar de trabajar.

Elvira. Sus abuelos fueron puesteros de estancia, su padre encargado de mantenimiento y su madre empleada doméstica. Elvira entró a trabajar en un centro cultural donde su padre hacía labores de mantenimiento y, a partir de ello, decidió estudiar la carrera de periodista. Una vez recibida, consiguió ser empleada en la radio del lugar redactando noticias. No ha tenido grandes cambios ni ascensos en su carrera laboral. El padre de sus hijos, que falleció en un accidente, era mecánico; su marido actual, chofer. Vive en una casa propia, en un barrio obrero de la zona oeste del Gran Buenos Aires. Cuando falleció su primer marido, Elvira atravesó durante años una difícil situación al quedarse sin recursos para pagar un crédito hipotecario, hasta que finalmente consiguió ayuda estatal.

Miriam. Nació en un hogar de medianos propietarios rurales en Santiago del Estero. Cuando tenía seis años padeció enfermedades respiratorias y su familia decidió llevarla a Buenos Aires para que sea tratada. La familia la dejó al cuidado de una tía que vivía en Buenos Aires. Con el paso del tiempo sus tíos pasaron a ser su familia adoptiva. Esta era una familia obrera urbana que alquilaba su vivienda. La economía familiar era frágil, porque el tío enfermó y solamente la tía proveía ingresos al hogar con su trabajo de modista, durante toda la infancia y adolescencia de Miriam. Miriam se recibió de docente al igual que sus hermanas que permanecieron con los padres biológicos. Muchos años después logró concluir una carrera universitaria, algo que habría querido realizar de joven pero que fue obstaculizado por las carencias económicas.

Marcelino. Su bisabuelo paterno había sido propietario de una estancia a principios del siglo $\mathrm{XX}$, de la que su abuelo heredó el casco y una porción de tierra laborable que se dedicó a trabajar como chacarero. Su padre fue un trabajador especializado en la clasificación de granos. Su madre, hija de un comerciante, era docente y llegó a ser inspectora escolar. Marcelino ha tenido varios emprendimientos comerciales bastante prósperos, uno de ellos en el rubro de la informática cuando la actividad recién comenzaba en el país. Sin embargo, con la crisis de 2001, su negocio dejó de funcionar bien. Por entonces se casó y tuvo una hija. La niña padece Síndrome de Down y desde su nacimiento requirió cuidados especiales que modificaron la vida cotidiana de la familia. Un accidente cerebrovascular que sufrió su esposa alteró más la vida de la familia. Luego de su recuperación, se separaron. Marcelino decidió vivir solo y abandonar el trabajo, porque padece trastornos psiquiátricos leves que le impiden mantener la calma ante dificultades cotidianas. Se sustenta con una renta y gastando ahorros. Esporádicamente vende algún mueble reciclado que fabrica como hobbie. 
Marcos. Sus abuelos varones de ambas ramas fueron estibadores portuarios. En el caso de su abuelo paterno, cuando perdió su empleo como estibador, trabajó como cartonero junto al padre de Marcos. Su padre fue obrero industrial muchos años hasta que cerró la fábrica y no consiguió otro empleo. Marcos tuvo varios empleos como obrero. Fue chofer de camión más de una década. Al principio como empleado, y luego decidió aceptar la oferta de comprar el camión y pasar a trabajar formalmente como independiente, aunque su único cliente era la empresa de la que había sido empleado. Cuando no pudo reparar el vehículo de una avería grave, quedó desocupado. Estuvo más de un año con un cuadro de depresión. Para salir adelante, con su esposa, hija de un comerciante, abrieron un quiosco de barrio, aprovechando un local desocupado de su suegro.

Pedro. A los pocos meses de haber nacido, su padre asesinó a su madre y fue preso. Pedro y su hermano fueron criados por tíos y también por desconocidos, en reformatorios y en la calle, padeciendo desprotección y violencia. Pedro aprendió el oficio de carnicero y aprendió a leer de adolescente. Ha llegado a tener su propia carnicería, aunque luego debió cerrarla y trabajar como remisero.

\section{Los efectos del tratamiento de la información en los datos y sus implicancias}

Veamos qué puede observarse en una tabla de movilidad para una población muy semejante a la nuestra: la cohorte de los nacidos entre 1960 y 1979 , residentes en el Área Metropolitana de Buenos Aires. Utilizando la base de datos del Programa de Investigación sobre la Sociedad Argentina Contemporánea (PISAC) del año 2015 y un esquema de clases habitual como el de Erikson, Goldthorpe y Portocarero, con categorías colapsadas en cuatro grandes clases, ${ }^{3}$ se obtienen los siguientes resultados.

En primer lugar, un índice de movilidad de $64 \%$. Sobre el total de casos, un $36 \%$ se concentró en la diagonal de la tabla, reproduciendo la posición de clase en este nivel de desagregación, un $41 \%$ en la parte inferior izquierda, indicando movilidad ascendente y un $23 \%$ por encima de la diagonal indicando movilidad descendente. 
Tabla de movilidad. Porcentajes de entrada (inflows). AMBA. Cohorte 1960-1979.

\begin{tabular}{|l|c|c|c|c|c|}
\hline & \multicolumn{4}{|c|}{ Clase EGP del encuestado } & \\
\hline $\begin{array}{l}\text { Clase EGP del } \\
\text { Principal Sostén } \\
\text { del Hogar }\end{array}$ & $\begin{array}{c}\text { Clase de } \\
\text { servicio }\end{array}$ & $\begin{array}{c}\text { Clase } \\
\text { intermedia }\end{array}$ & $\begin{array}{c}\text { Clase } \\
\text { obrera } \\
\text { alta }\end{array}$ & $\begin{array}{c}\text { Clase } \\
\text { obrera } \\
\text { baja }\end{array}$ & Totales \\
\hline Clase de servicio & $36 \%$ & $10 \%$ & $4 \%$ & $3 \%$ & $14 \%$ \\
\hline Clase intermedia & $34 \%$ & $35 \%$ & $30 \%$ & $30 \%$ & $33 \%$ \\
\hline Clase obrera alta & $15 \%$ & $21 \%$ & $19 \%$ & $21 \%$ & $19 \%$ \\
\hline Clase obrera baja & $15 \%$ & $34 \%$ & $47 \%$ & $46 \%$ & $34 \%$ \\
\hline Totales & $100 \%$ & $100 \%$ & $100 \%$ & $100 \%$ & $100 \%$ \\
& $(382674)$ & $(430111)$ & $(188051)$ & $(401850)$ & $(1402686)$ \\
\hline
\end{tabular}

Fuente: elaboración propia en base a la encuesta PISAC 2014. Total de la submuestra: 526 casos. Se aplicó el factor de expansión a la población para corregir cuestiones muestrales.

En segundo lugar, si se observa de dónde se reclutan los que comparten una posición de clase actual, en todas las clases hay entre un 30 y un $35 \%$ que provienen de la clase intermedia y entre un 15 y un $21 \%$ que provienen de la clase obrera alta. Para las dos fracciones obreras, casi la mitad ( 47 y $46 \%$ ) provienen de la clase obrera baja. En la clase obrera alta solo un $4 \%$ tuvo un origen en la clase de servicio y en la clase obrera baja sólo un $3 \%$, en cambio en la clase de servicio un $36 \%$ se reclutó en esa misma clase.

Tabla de movilidad. Porcentajes de salida (outflows). AMBA. Cohorte 1960-1979.

\begin{tabular}{|l|c|c|c|c|l|}
\hline & \multicolumn{4}{|c|}{ Clase EGP del encuestado } & \\
\hline $\begin{array}{l}\text { Clase EGP del } \\
\text { Principal Sostén } \\
\text { del Hogar }\end{array}$ & $\begin{array}{c}\text { Clase } \\
\text { de } \\
\text { servicio }\end{array}$ & $\begin{array}{c}\text { Clase } \\
\text { intermedia }\end{array}$ & $\begin{array}{c}\text { Clase } \\
\text { obrera } \\
\text { alta }\end{array}$ & $\begin{array}{c}\text { Clase } \\
\text { obrera } \\
\text { baja }\end{array}$ & Totales \\
\hline Clase de servicio & $69 \%$ & $22 \%$ & $4 \%$ & $5 \%$ & $\begin{array}{l}100 \% \\
(199448)\end{array}$ \\
\hline Clase intermedia & $29 \%$ & $33 \%$ & $12 \%$ & $26 \%$ & $\begin{array}{l}100 \% \\
(458704)\end{array}$ \\
\hline Clase obrera alta & $21 \%$ & $33 \%$ & $14 \%$ & $32 \%$ & $\begin{array}{l}100 \% \\
(267945)\end{array}$ \\
\hline Clase obrera baja & $12 \%$ & $31 \%$ & $18 \%$ & $39 \%$ & $\begin{array}{l}100 \% \\
(476589)\end{array}$ \\
\hline Totales & $27 \%$ & $31 \%$ & $13 \%$ & $29 \%$ & $\begin{array}{l}100 \% \\
(1402686)\end{array}$ \\
\hline
\end{tabular}

Fuente: elaboración propia en base a la encuesta PISAC 2014. Total de la submuestra: 526 casos. Se aplicó el factor de expansión a la población para corregir cuestiones muestrales. 
Comparando los marginales de ambas tablas, se observa que casi se duplicó el tamaño de la clase de servicio y se redujo alrededor de un tercio el tamaño de la clase obrera alta o calificada. El tamaño de las otras dos categorías se redujo levemente.

Por último para nuestros fines, veamos los porcentajes de herencias. Casi 7 de cada 10 personas con origen en la clase de servicio y 4 de cada 10 de la clase obrera baja mantuvieron sus respectivas posiciones, lo que indica mayor reproducción de clase en los extremos. Solamente $9 \%$ de los de origen en la clase de servicio tuvo alguna fracción obrera como destino. Entre los de origen de clase intermedia hubo tres destinos de similar importancia: reproducción en la misma clase intermedia (33\%), clase de servicio ( $29 \%$ ) y clase obrera baja (26 $\%)$. Este último podría deberse en parte a que todo un sector de autoempleados de subsistencia hayan sido clasificados como trabajadores autónomos. Por otra parte, la clase obrera alta fue el único origen para el cual la reproducción de clase no solo no constituyó el destino más probable, sino por el contrario el menos probable (14\%), lo cual evidentemente se vincula con la fuerte reducción del estrato en la estructura ocupacional. Los hijos de obreros calificados descendieron a la clase obrera baja o pasaron a la clase intermedia casi con la misma probabilidad (32 \% y $33 \%$ ). A grandes rasgos, la distribución de los que tuvieron origen en la clase obrera baja se asemeja a la de la fracción obrera alta, salvo en que llegan menos a la clase de servicio ( $12 \%$ contra $21 \%$ ).

Veamos ahora dónde quedarían ubicados en una tabla así nuestros entrevistados:

\begin{tabular}{|l|c|c|}
\hline & \multicolumn{2}{|c|}{ Clase EGP encuestado } \\
\hline Clase EGP del & Clase de servicio & Clase intermedia \\
Principal Sostén del & & \\
\hline Clase de servicio & Carlos/Lucas & Felipe \\
\hline Clase intermedia & Lara & Domingo/Ricardo \\
\hline Clase obrera alta & Elvira/Miriam & Marcelino/Marcos \\
\hline
\end{tabular}

Carlos y Lucas, en la esquina superior izquierda, representarían la reproducción en la clase de servicio, lo que efectivamente se verifica en sus historias, aunque con una diferencia entre ellos: mientras que Carlos se desvinculó tempranamente de su familia de origen, Lucas mantuvo el vínculo. Esa diferencia cualitativa resultó relevante respecto al tipo de proceso implicado en cada trayectoria y a los recursos familiares a disposición para los agentes individuales.

En el caso de Felipe la pendiente descendente de su trayectoria también aparece "correctamente" reflejada en la tabla. Más allá de que el esquema de Goldthorpe 
no pretenda ser gradacional-jerárquico, en la práctica la interpretación usual de la movilidad se hace en estos términos. Sin embargo, el pasaje de la clase de servicio (su padre fue gerente en una de las empresas más importantes de Argentina) a la clase "intermedia" (trabaja por cuenta propia) no parece expresar acabadamente la intensidad del desclasamiento que su relato de vida muestra.

En el caso de Lara, en la tabla se observaría un ascenso de la clase intermedia a la clase de servicio. Efectivamente Lara ha ascendido en la dimensión de capital cultural y logró un nivel educativo superior a sus padres. Sin embargo, en esa historia había ocurrido algo más: una descapitalización económica intergeneracional donde la familia pasó de ser propietaria de varios comercios e inmuebles a que su padre en la última etapa de su vida laboral haya tenido su única fuente de ingresos en un empleo asalariado no calificado como vigilador privado.

Domingo y Ricardo, de acuerdo a la tabla, reprodujeron su posición de clase intermedia (sus padres comerciantes y ellos también). Sin embargo, los dos casos tuvieron trayectorias bien distintas entre sí y con respecto a la presunta inmovilidad que la tabla indica. Domingo padeció un importante empobrecimiento, su puesto de flores produce ingresos insignificantes, menores que un salario, o directamente pérdidas en algunos meses. Su padre, en cambio, aun con los vaivenes, había tenido épocas de prosperidad y más de un comercio. Ricardo, por su parte, en realidad ya no es más comerciante, sino rentista. Un rentista no tiene ocupación y no es empleador, por lo tanto, no puede ser clasificado en la clase de servicio. Si no se quiere dar por perdido el caso para el análisis cuantitativo, se toma "la ocupación del hogar" o bien su último trabajo; en cualquiera de esas situaciones le corresponde la clase intermedia. El importante ascenso económico respecto a su padre no es captado en una tabla de movilidad como esta y, además, quedaría clasificado en el mismo espacio de propiedades que Domingo, quien tuvo una trayectoria inversa.

Elvira y Miriam habrían ascendido de acuerdo a la tabla de la clase obrera a la clase de servicio. Nuevamente, ello podría relativizarse y por distintos motivos en cada caso. El ascenso experimentado por Elvira ocurrió de joven al recibirse y conseguir empleo como periodista. Desde entonces su situación económica ha empeorado respecto a la de su familia de origen, las deudas le significaron una pesada carga y no ha tenido una "carrera" laboral, aunque sí conservó el empleo como franquera en la radio. Vive en un barrio obrero, sus parejas han sido obreros y su trayectoria se ha caracterizado por estar al borde del descenso. En el caso de Miriam, cuando tenía 15 años no vivía con sus padres sino con su tía, que era costurera. Con respecto a ella ha ascendido a una posición más elevada, pero su doble origen permite entender mejor las condiciones en que se desenvolvió su trayectoria.

Por último, Marcelino y Marcos, dos casos distintos en su origen y su situación presente, también quedarían clasificados juntos en la tabla. Marcelino si bien tenía un padre obrero que era el principal sostén del hogar, su madre era directora de escuela y sus abuelos paternos tenían un casco de estancia, por lo cual la posición de origen no era estrictamente obrera. Respecto a su posición actual, vive de una renta y de algunos trabajos artesanales que realiza como hobbies desde que decidió abandonar sus actividades en el mercado. Por su parte, Marcos constituye otro caso de pequeño comerciante "de subsistencia", donde el negocio no es rentable. En su caso, el local es de la familia de su esposa y la decisión de 
abrir un quiosco estuvo motivada principalmente por encontrarle a Marcos una ocupación para que saliese de la depresión tras quedar desocupado, un panorama bastante distinto a la movilidad ascendente.

Por las convenciones de codificación hay casos que "no tienen" origen de clase, como Pedro, que a los 15 años hacía rato que ya no vivía con sus padres ni con alguien de rol equiparable en el hogar.

Probablemente otros esquemas de clase puedan superar algunos de estos problemas, pero a menudo sustituirían unas dificultades por otras. Esto no significa que no sean útiles las tablas de movilidad o los análisis cuantitativos de la movilidad social. Sirven a condición de no autonomizar las técnicas de la metodología y la teoría, de no olvidar que los cálculos de porcentajes -así como de las oportunidades relativas y la evaluación del ajuste de los modelos log-linealesse realizan sobre datos manufacturados en base a decisiones que, al conocer los casos en profundidad, pueden problematizarse.

\section{Discusión}

El análisis de las desigualdades puede llevarse a cabo desde distintos enfoques teóricos y metodológicos. Entre las ventajas de un abordaje macrosociológico se destaca la posibilidad de ofrecer una imagen de la estructura social, del conjunto de posiciones jerarquizadas que condicionan a los agentes individuales y colectivos. En el abordaje microsociológico pueden ponerse de relieve las determinaciones concretas al identificarlas en casos particulares, examinando sus variaciones, las articulaciones entre condicionamientos de distinto tipo y los momentos y circunstancias precisas en que se activaron. La dimensión objetiva de la vida social y la dimensión subjetiva, parcialmente yuxtapuestas con las nociones de estructura y acción, pueden ser estudiadas desde abordajes macro o micro sociales. Por ejemplo, una posibilidad es conocer aspectos subjetivos y conductas desde una perspectiva macrosocial, con una metodología cuantitativa, midiendo el peso relativo y los determinantes de ideologías, actitudes, representaciones, tomas de posición, o bien prácticas, condiciones de la acción, consecuencias, etc. De manera análoga, los aspectos objetivos y estructurales pueden ser conocidos por la vía indirecta de la perspectiva microsocial y/o con una metodología cualitativa, como es el caso del enfoque sobre los casos particulares mediante relatos de vida. Este camino a contramano pretende encontrar la estructura social y las desigualdades en la vida cotidiana. El redescubrimiento de lo conocido puede contribuir a resituar algunas preguntas sobre las desigualdades o a reexaminar el alcance de las modalidades más corrientes e instituidas para buscar las respuestas.

Los esquemas predefinidos de clases sociales no siempre resultan satisfactorios. Las categorizaciones previas son una exigencia en la mayoría de las investigaciones cuantitativas en estructura y movilidad social para fijar los orígenes de clase, para medir las distancias, para evaluar la bondad del ajuste de los modelos, para comparar con otros estudios, en suma: para estandarizar. En cierto sentido, también lo son en indagaciones cualitativas. Aun disponiendo de toda la información una vez construido cada relato de vida, la ubicación de los casos en una posición de clase como punto de partida del análisis resulta siempre problematizable. Un procedimiento habitual como la codificación de la ocupación para asignar una posición de clase puede resultar insuficiente para 
captar algunos aspectos implicados en las nociones teóricas, por ejemplo, las múltiples formas de capital, los desplazamientos en el espacio social a través del tiempo y los vínculos familiares que conforman la posición mediata de clase. La construcción de un índice sumatorio no resuelve el problema porque se perderían en el resultado las contribuciones de cada aspecto, además de la arbitrariedad en la asignación de puntajes a los distintos atributos.

Supongamos que para determinar una posición de clase de origen se toma como referencia la ocupación de los padres de un entrevistado cuando este tenía 15 años de edad -como suele realizarse en estudios cuantitativos de movilidad social-. Varias trayectorias similares podrían ser clasificadas en distintos orígenes de clase solamente por cierta divergencia temporal entre unas y otras. La heterogeneidad de clase de las parejas de padres agrega una complejidad adicional para situar a un caso en una posición de origen. A ello debe añadirse luego el papel del resto de las relaciones familiares que conforman la clase. No son pocos los casos donde una posición de clase obrera de uno de los padres queda relativizada al observar que los abuelos del entrevistado eran comerciantes, pequeños propietarios, etc. Esto puede tener consecuencias en las interpretaciones respecto a la existencia de movilidad social. No es lo mismo un reenclasamiento, una recuperación de una posición en la estructura social previamente ocupada por miembros de la familia que un proceso de ascenso social sin precedentes familiares. El peso relativo que se le asigna al capital económico y al capital cultural también produce cierta indeterminación en las posiciones sociales. Un proceso de movilidad social de "larga distancia" identificado desde el punto de vista ocupacional puede revelarse como de "corta distancia" o incluso de reproducción de la posición relativa al observar el patrimonio cultural familiar.

La dificultad para establecer inequívocamente qué posición de clase ocupa un individuo o una familia y el tipo de trayectoria de movilidad social genera la posibilidad de que un conjunto de casos pueda ser clasificado de distinto modo, con distintas distancias sociales entre sí, según los criterios que se tomen. Estas decisiones teórico-metodológicas son aceptables e inevitables en todo proceso de investigación, a condición de advertir los efectos en los resultados. Con distintos criterios clasificatorios se configuran distintos "mapas de clases" para un mismo conjunto de casos. La movilidad social que luego se encuentre en cada mapa de clases depende de las distancias relativas debidas a los criterios seleccionados, que podrían estar sesgados respecto a ciertos factores.

No todos los sesgos se anulan o compensan con el tratamiento estadístico de los casos. Del mismo modo que en un diseño experimental hay una suposición contrafáctica de que los resultados en el grupo experimental habrían sido los mismos que los del grupo de control de no haberse sometido el primero al tratamiento o estímulo, en el análisis de movilidad social convencional hay una suposición contrafáctica cuando se halla que algunos casos presentan movilidad social y otros no, es decir: se asume que efectivamente la posición de origen era la misma y que las diferencias no estaban previamente. Cuando en vez del análisis estadístico se examina la movilidad social con el abordaje de los relatos de vida, esto se pone de relieve en la inclinación a buscar que las posiciones de origen de dos casos que exhibieron trayectorias distintas ya eran diferentes desde antes, hurgando en los detalles que ofrecerían las pistas de las determinaciones estructurales, la movilidad social "en potencia”, casi invisible pero presente desde 
antes que se despliegue. La conciencia respecto a las distintas posibilidades clasificatorias obliga a preguntarse por las diferencias entre los casos homogéneos y por las similitudes entre casos heterogéneos.

Un problema especial de los esquemas de clases lo constituyen las fronteras entre ellas. Las distintas desigualdades en la realidad social se presentan a la manera de ejes con polos sin solución de continuidad entre ellos. Las posiciones en el espacio social forman un continuum. Aunque algunos criterios clasificatorios como la posesión de vivienda propia o el carácter de empleador puedan ofrecer cortes tajantes, el conjunto de criterios tiende a la proliferación de combinaciones que multiplican las situaciones intermedias entre posiciones. Si se toma un único criterio, como la propiedad de medios de producción, aunque no dejen de existir situaciones fronterizas, probablemente la mayoría de los casos puedan ser clasificados con cierta facilidad. Cuando, en cambio, se consideran múltiples dimensiones para establecer la posición social, las situaciones intermedias respecto a por lo menos un criterio se hacen mucho más probables, así como las discrepancias o "situaciones contradictorias" entre las posiciones definidas entre unas y otras dimensiones.

El examen detenido de los casos concretos conduce a cuestionar la nitidez de las fronteras de clase. Una concepción realmente multidimensional de las clases sociales implica el desafío de cambiar los modelos mentales acerca de qué son las clases sociales, los modos sustancialistas de pensamiento sobre las clases (Bourdieu, 2000). En vez de dar por sentado un criterio o buscar el criterio que mejor funcione empíricamente para demarcar clases, puede resultar más provechoso para el análisis de clase prescindir de una demarcación en particular y usar alternativamente unas y otras combinaciones. En definitiva, es eso lo que diferencia a las clases como sistema de estratificación social de otros como estamentos o castas, con definiciones mucho más precisas porque están formalmente sancionadas. Asumir el carácter indeterminado y difuso de las fronteras de clases, a modo de una paleta cromática donde no se puede fijar de una sola manera dónde termina una familia de colores y dónde comienza otra, elude los equívocos y discusiones bizantinas respecto a cuáles serían las verdaderas clases, por ejemplo, cuando se pretende distinguir entre clases reales y meras mistificaciones ideológicas, impugnando el uso de algunas categorías por no constituir clases con entidad histórica. Para reconocer una clase en el sentido teórico, como conjunto de posiciones que comparten una situación objetiva, no es necesario que la clase esté movilizada, que constituya un sujeto histórico o una fuerza social. Ello no quiere decir que ese conjunto de posiciones no tenga una historia. La división de clases empleada en el análisis sociológico es una apuesta teórica a una forma de fragmentación del espacio social entre otras posibles. Una clasificación no es verdadera ni falsa, a lo sumo más o menos útil, más o menos válida según su correspondencia con otros criterios.

Se abre la posibilidad, por ejemplo, de reconocer la existencia de una clase trabajadora en sentido amplio, fragmentada en distintas subjetividades productivas, donde profesionales, gerentes y pequeños propietarios pueden ser concebidos como las fracciones privilegiadas de una misma gran clase trabajadora junto a los obreros, incluso los más precarios (Iñigo Carrera, 2008). Las enormes distancias en magnitud del capital económico poseído por los primeros respecto al capital de la gran burguesía global habilitarían a reunir con determinada 
finalidad analítica a gerentes o patrones de pequeños establecimientos con obreros en una misma clase teórica. En el extremo opuesto, tal como el análisis neodurkheimiano de Grusky propone (Grusky y Galescu, 2005), podrían desagregarse las clases en categorías ocupacionales, si se considera que es en esa escala donde se encuentran las similitudes más relevantes para otro tipo de análisis. En definitiva, se trata de admitir toda la flexibilidad posible en las clases teóricas o clases en el papel, evitando prejuzgar como disparatadas, poco razonables o distorsionadas divisiones de clase menos exploradas y que pueden resultar útiles para revelar lo que ocultan las divisiones más convencionales. Cierto anarquismo metodológico respecto a cuáles son las diferencias que importan en el análisis de clase puede contribuir al modo de entender las desigualdades. La concepción de un espacio social de permanentes transiciones entre posiciones habilita a suponer tanto una gran y heterogénea clase trabajadora que abarca a la mayoría de la población como a innumerables pequeñas clases basadas en las ocupaciones u otros criterios. De este modo no se desconocen o relativizan las desigualdades, sino que se representan de manera flexible procurando adecuar las categorizaciones a las distribuciones reales y a los intereses cognoscitivos.

Esta concepción de un espacio social sin delimitaciones incuestionables, donde distintos criterios son legítimos y admisibles, se vuelve más necesaria cuando se trata de incorporar otros ejes de desigualdad que interactúan con las clases. La interseccionalidad entre clase y género u otros principios de desigualdad fuerza a repensar las jerarquizaciones y complejizarlas. Ello puede ocasionar reticencias ideológicas y políticas por las modificaciones en las posiciones entre dominantes y dominados que potencialmente implica. Cuantos más ejes de opresión se agreguen, más se diluye cada uno de ellos entre los demás y se presenta entonces el problema de determinar los pesos relativos en las imbricaciones concretas. A cambio, la mirada interseccional abre la posibilidad de un pensamiento que asuma las heterogeneidades sin paralizarse por las aparentes contradicciones. El problema teórico de los límites y agrupamientos en las clasificaciones de posiciones tiene su correlato en el problema político de las alianzas de los oprimidos y subalterizados en distintos ejes de desigualdad.

\section{Referencias}

Beccaria, L. (1978). Una contribución al estudio de la movilidad social en la Argentina. Análisis de los resultados de una encuesta para el Gran Buenos Aires. Desarrollo económico, 17(68), 593-618.

Bertaux, D. y Thompson, P. (ed.) (2007). Pathways to social class. A qualitative approach to social mobility. New Brunswick, Canadá: Transaction Publishers.

Bourdieu, P. (2000). ¿Cómo se hace una clase social? Sobre la existencia teórica y práctica de los grupos. En Poder, derecho y clases sociales. Bilbao, España: Desclée de Brouwer.

Cachón Rodríguez, L. (1989). ¿Movilidad social o trayectorias de clase? Elementos para una crítica de la sociología de la movilidad social. Madrid, España: CIS-Siglo XXI.

Chávez Molina, E., Pla, J., y Molina Derteano, P. (2011). Entre la adscripción, la estructura y el logro, determinantes de la movilidad social: Ministro Rivadavia, Sur 
del Gran Buenos Aires, 2008-2009. Lavboratorio: revista de estudios sobre cambio estructural y desigualdad social, 24, 103-118.

Dalle, P. (2016). Movilidad social desde las clases populares: Un estudio sociológico en el Area Metropolitana de Buenos Aires, 1960-2013. Buenos Aires: CLACSO; Instituto de Investigaciones Gino Germani.

Erikson, R., Goldthorpe, J. y Portocarero, L. (1979). Intergenerational class mobility in three Western European societies: England, France and Sweden. The British Journal of Sociology, 30(4), 415-441.

Germani, G., Mera, C., y Rebón, J. (2010). Gino Germani, la sociedad en cuestión: antología comentada. Buenos Aires: CLACSO.

Grusky, D. y Galescu, G. (2005) Foundations of a neo-durkheimian class analysis. En E. Wright (Comp), Approaches to Class Analysis. Cambridge, Inglaterra: Cambridge University Press.

Gutiérrez, A. (2015). Pobre'... como siempre: estrategias de reproducción social en la pobreza. Villa María: Eduvim.

Jacinto, C. (comp.) (2010). La construcción social de las trayectorias laborales de jóvenes: politicas, instituciones, dispositivos y subjetividades. Buenos Aires: IDES-Teseo.

Jiménez Zunino, C. y Assusa, G. (2017). ¿Desigualdades de corta distancia? Trayectorias y clases sociales en Gran Córdoba, Argentina. Revista Mexicana de Sociología, 79(4), 837-874.

Jorrat, J. R. (2000). Estratificación social y movilidad: Un estudio del área metropolitana de Buenos Aires. Tucumán: Universidad Nacional de Tucumán.

Kessler, G. (2014). Controversias sobre la desigualdad: Argentina, 2003-2013. Buenos Aires: Fondo de Cultura Económica.

Iñigo Carrera, J. (2008). El capital: razón histórica, sujeto revolucionario y conciencia. Buenos Aires, Argentina: Imago Mundi.

Muñiz Terra, L. (2016). Refiguración e incertidumbre: carreras laborales de dos generaciones de trabajadores. Revista mexicana de sociologia, 78(4), 577-603.

Pla, J. (2016). Condiciones objetivas y esperanzas subjetivas. Movilidad social y marcos de (in) certidumbre. Un abordaje multidimensional de las trayectorias de clase. Argentina durante la primera década del siglo XXI. Buenos Aires: Editorial Autores de Argentina.

Sautu, R. (1992). Teoria y medición del estatus ocupacional. Escalas ocupacionales objetivas $y$ de prestigio (Cuadernos del Instituto de Investigaciones $N^{o}$ 10). Buenos Aires: Facultad de Ciencias Sociales, Universidad de Buenos Aires.

Seid, G. (2017). Transmisiones y apuestas educativas en trayectorias de clase social desde familias obreras. Boletin Científico Sapiens Research, 7(1), 89-97.

Seid, G. (2021). Sombras de la bancarrota: trayectorias de desclasamiento en familias de pequeños comerciantes en Buenos Aires. Sociologia On Line, 25, 35-61.

Torrado, S. (1992). Estructura social de la Argentina, 1945-1983. Buenos Aires: Ediciones de la Flor.

\section{Notas}

1 Este último texto surgió de la transcripción de una conferencia de Bourdieu en 1987 en la Universidad de Chicago. Se publicó su versión traducida al inglés en el Berkeley Journal of Sociology con el titulo What makes a social class? On the theoretical and practical existence of groups. Posteriormente la primera parte del título ha sido traducida al español ¿Cómo se hace una clase social? por Daniel Oliver Lalana en un libro de 
la editorial Desclée de Brouwer que contiene el texto; mientras que en la Revista Paraguaya de Sociología Rubén Urbazagástegui Alvarado lo había traducido ¿Qué es lo que hace una clase social? Esta última traducción parece más fiel a la intención del título, pero la primera puede resultar más sugerente.

2 Pueden consultarse en Seid (2017) y Seid (2021).

3 Se utilizó el agrupamiento de 3 clases del esquema Goldthorpe, Erikson y Portocarero, pero la clase obrera se subdividió en dos. De este modo, la clase de servicio incluye la I (alta) y la II (baja). La clase intermedia incluye la IIIa (trabajadores no manuales de rutina, alta), la IVa (autónomos con empleados), la IVb (autónomos sin empleados) y la V (supervisores de trabajadores manuales). La clase obrera alta incluye la IIIb (trabajadores no manuales de servicios y comercio, baja) y la VI (trabajadores manuales calificados). La clase obrera baja incluye la VIIa (trabajadores manuales no calificados) y la VIIb (trabajadores agropecuarios). 